\title{
Biological and clinical effects of abiraterone on anti-resorptive and anabolic activity in bone microenvironment
}

\author{
Michele Iuliani ${ }^{1, *}$, Francesco Pantano ${ }^{1, *}$, Consuelo Buttigliero ${ }^{2}$, Marco Fioramonti ${ }^{1}$, \\ Valentina Bertaglia ${ }^{2}$, Bruno Vincenzi ${ }^{1}$, Alice Zoccoli ${ }^{1}$, Giulia Ribelli ${ }^{1}$, Marcello \\ Tucci $^{2}$, Francesca Vignani², Alfredo Berruti ${ }^{3}$, Giorgio Vittorio Scagliotti², Giuseppe \\ Tonini $^{1}$ and Daniele Santini ${ }^{1}$ \\ ${ }^{1}$ Translational Oncology Laboratory, Medical Oncology, University Campus Bio-Medico of Rome, Rome, Italy \\ 2 Department of Oncology, University of Turin, San Luigi Hospital, Orbassano, Turin, Italy \\ ${ }^{3}$ U.O. Oncologia Medica, Ospedali Civili di Brescia, Brescia, Italy \\ * These authors have contributed equally to this work \\ Correspondence to: Daniele Santini, email: d.santini@unicampus.it \\ Keywords: abiraterone acetate, osteoclast, osteoblast, bone marker \\ Received: February 06, $2015 \quad$ Accepted: March 03, $2015 \quad$ Published: March 30, 2015
}

This is an open-access article distributed under the terms of the Creative Commons Attribution License, which permits unrestricted use, distribution, and reproduction in any medium, provided the original author and source are credited.

\section{ABSTRACT}

Abiraterone acetate (ABI) is associated not only with a significant survival advantage in both chemotherapy-naive and -treated patients with metastatic castration-resistant prostate cancer (MCRPC), but also with a delay in time to development of Skeletal Related Events and in radiological skeletal progression. These bone benefits may be related to a direct effect on prostate cancer cells in bone or to a specific mechanism directed to bone microenvironment. To test this hypothesis we designed an in vitro study aimed to evaluate a potential direct effect of ABI on human primary osteoclasts/osteoblasts (OCLs/OBLs). We also assessed changes in bone turnover markers, serum carboxy-terminal collagen crosslinks (CTX) and alkaline phosphatase (ALP), in 49 mCRPC patients treated with ABI.

Our results showed that non-cytotoxic doses of ABI have a statistically significant inhibitory effect on OCL differentiation and activity inducing a down-modulation of OCL marker genes TRAP, cathepsin K and metalloproteinase-9. Furthermore ABI promoted $O B L$ differentiation and bone matrix deposition up-regulating OBL specific genes, ALP and osteocalcin. Finally, we observed a significant decrease of serum CTX values and an increase of ALP in ABI-treated patients.

These findings suggest a novel biological mechanism of action of ABI consisting in a direct bone anabolic and anti-resorptive activity.

\section{INTRODUCTION}

Several anticancer agents directly influence bone remodeling targeting specific bone cells such as osteoclasts (OCLs), osteoblasts (OBLs), osteocytes and, concomitantly, resulting in bone anabolic and anticatabolic therapeutic effects. In this context, a number of bone-targeted agents are currently under preclinical and clinical investigation such as c-Src inhibitors, integrins inhibitors, cathepsin-K inhibitors, endothelin receptor antagonists and WNT signaling pathway modulators [1].

Abiraterone acetate $(\mathrm{ABI})$ is a selective androgen biosynthesis inhibitor that potently and irreversibly blocks Cyp17 resulting in virtually undetectable serum and intratumoral androgen production in the adrenals, testes and prostate cancer cells $[2,3]$. In phase III studies in metastatic castration-resistant prostate cancer (mCRPC) patients, it was demonstrated that $\mathrm{ABI}$ treatment is associated not only with a significant survival advantage in both chemotherapy-naive and chemotherapy-treated patients [4-6] but also, in docetaxel treated patients, with a better pain control from skeletal metastases, a delay in time to development SREs and in radiological skeletal progression. More specifically, $25 \%$ of patients developed 
a skeletal event in 9.9 months when treated with ABI and 4.9 months with placebo and time to first SRE was 25.0 months with ABI compared to 20.3 months with placebo $[4,5]$. These ABI effects on metastatic bone disease may be secondary to a systemic control of the disease due to a direct antitumor effect that, in turns, leads to a decrease of cancer cells/OCLs/OBLs vicious circle or, alternatively, to a specific action directed to bone microenvironment. To test this second hypothesis we have designed a translational study aimed to investigate a potential bone direct effect of $\mathrm{ABI}$ in an in vitro model of human primary OCLs/OBLs and in a prospective cohort of castration resistant prostate cancer patients in which bone turnover markers were assessed during ABI treatment.

\section{RESULTS}

\section{Cyp17a1 and androgen receptor expression during osteoclast and osteoblast differentiation}

Cyp17a1 expression was evaluated at different stages of osteoclast/osteoblast differentiation by real-time PCR. Osteoclast mRNA levels were assessed at three different time-points during the differentiation protocol [day 0 (monocyte), day 6 (pre-osteoclast), day 12 (mature osteoclast)] as well as its expression in the osteoblasts was evaluated at day 0 (mesenchymal cells), day 14 (preosteoblast) and day 21 (mature osteoblast). Cyp17A1 was expressed during all phases of osteoclast/osteoblast maturation with a significant increase of mRNA levels at early stage of osteoclast differentiation (monocytes vs preOCL $p<0.0001$; monocytes vs OCL $p<0.0001$ ) (Fig. S1). Conversely Cyp17a1 mRNA levels remained unchanged during the osteoblast maturation process (Fig. S1). During OCLs/OBLs differentiation Androgen Receptor (AR) expression levels were also assessed because it was shown by others a direct activity of steroids on bone cells [7-12]. AR was expressed at different stages of osteoclast differentiation with a significant decrease in the levels of transcripts in the mature osteoclasts (monocytes vs OCL $p<0.001)$. Similarly to what observed for Cyp17a1, AR mRNA levels were stable during all the phases of OBLs differentiation (Fig. S1).

\section{Effect of ABI on primary osteoclast differentiation and activity in presence or absence of steroids}

ABI was administered to primary cells at two different concentrations, $5 \mu \mathrm{M}$ and $10 \mu \mathrm{M}$ similarly to other preclinical studies that tested $10 \mu \mathrm{M}$ as maximum dose in in vitro assays [13-15]. Both doses did not impact on
A

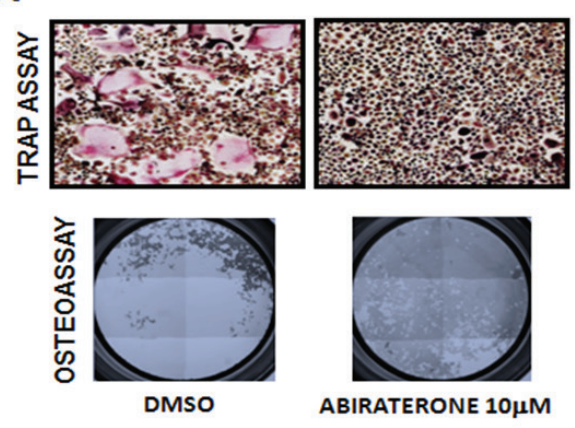

B

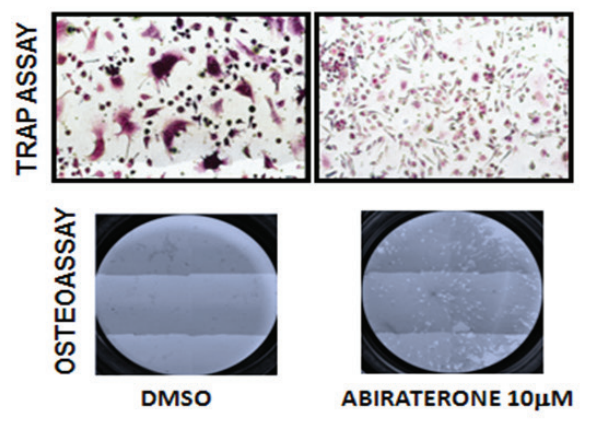

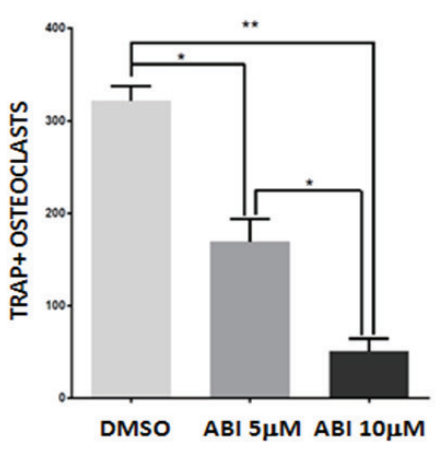
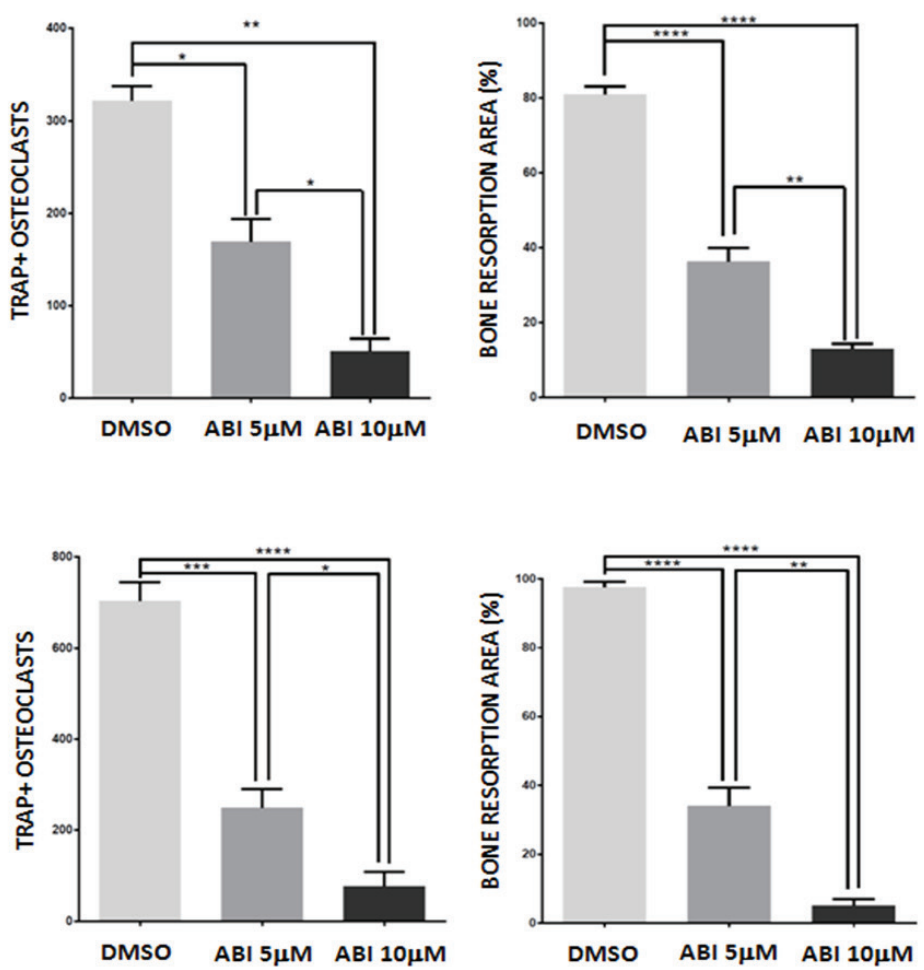

Figure 1: Effect of abiraterone treatment on primary osteoclast. TRAP and Osteoassay in treated and untreated osteoclasts (DMSO) in presence $(\mathbf{A})$ and absence $(\mathbf{B})$ of steroids. $*(P<0.05) * *(P<0.001) * * *(P<0.0001) * * * *(P<0.00001)$. 
Table 1: Patients characteristics.

\begin{tabular}{|l|l|}
\hline Age (median) & $\mathbf{6 7}$ years \\
\hline Gleason score (GS): & Patients \\
$=7$ & 16 \\
$<7$ & 6 \\
$>7$ & 23 \\
Unknown & 4 \\
\hline Metastasis: & Patients \\
bone & 16 \\
bone and lymph node & 18 \\
lymph node & 9 \\
bone and visceral & 3 \\
visceral & 1 \\
bone and local recurrence & 1 \\
bone, visceral and lymph node & 1 \\
\hline Zoledronic acid treatment & Patients \\
during ABI & 20 \\
\hline ECOG PS: & Patients \\
0 & 31 \\
1 & 15 \\
2 & 3 \\
\hline
\end{tabular}

osteoclast viability excluding a possible cytotoxic effect (Fig. S3). ABI was added to osteoclast cell cultures every 3 days and osteoclast differentiation was evaluated at the end of the differentiation protocol (day 12) by functional TRAP assay. ABI treatment had a statistically significant inhibitory effect on osteoclast maturation reducing the number of mature TRAP+ osteoclasts compared with control (DMSO) (DMSO vs ABI $5 \mu \mathrm{M} p<0.05$; DMSO vs ABI $10 \mu \mathrm{M} p<0.001$; ABI $5 \mu \mathrm{M}$ vs ABI 10 $\mu \mathrm{M} p=0.032)($ fig. $1 \mathrm{~A})$. The effect of ABI treatment on osteoclastic activity was tested by seeding monocytes on wells coated with inorganic calcium phosphate to mimic bone matrix and evaluating the reabsorbed areas (pits) produced by osteoclasts at the end of the differentiation protocol. ABI significantly inhibited bone resorption interfering with osteoclast function (DMSO vs ABI $5 \mu \mathrm{M}$ $p<0.0001$; DMSO vs ABI $10 \mu \mathrm{M} p<0.0001$; ABI $5 \mu \mathrm{M}$ vs $\mathrm{ABI} 10 \mu \mathrm{M} \mathrm{p}=0.020$ ) (fig.1A). Moreover, the effect of $\mathrm{ABI}$ on osteoclast differentiation and activity was also assessed using a charcoal-treated serum to deplete the steroid content in the culture medium. In this deprivation status the rate of mature osteoclasts significantly increased as well as the ability of these cells to reabsorb bone matrix $(p<0.001)$ (Fig. S2). In such deprivation model, TRAP and resorption assay confirmed the anti-resorptive action of ABI suggesting an androgen-independent inhibitory mechanism (Fig. 1B).

\section{Effect of ABI on primary osteoblast differentiation and activity in presence or absence of steroids}

The effect of ABI on osteoblastic differentiation has been evaluated in both presence and absence of steroids using ALP assay that allows identifying the expression of ALP, the main enzyme marker for osteoblasts. Following ABI treatment osteoblast cultured in steroid- containing medium showed a significant increase in the ALP positivity (DMSO vs ABI $5 \mu \mathrm{M} \mathrm{p}=0.035$; DMSO vs $A B I 10 \mu \mathrm{M} \mathrm{p}=0.30$ ) (Fig. 2A). Osteoblast ability to produce bone matrix was analyzed only in presence of androgen since steroid deprivation made cells unable to induce calcium phosphate deposits. ABI increased significantly bone matrix deposition stained by Alizarin red assay (DMSO vs ABI $5 \mu \mathrm{M} \mathrm{p}=0.026$; DMSO vs ABI $10 \mu \mathrm{M} \mathrm{p}=0.014)$ (Fig. 2A). These data demonstrated that, unlike osteoclasts, osteoblasts require a source of steroids to reach the complete differentiation, although $\mathrm{ABI}$ treatment results in a partial differentiation rescue in the steroid- depleted condition suggesting an androgenindependent anabolic effect of ABI. Indeed following $\mathrm{ABI}$ administration the percentage of ALP+ osteoblasts was significantly increased compared to control (DMSO vs $\mathrm{ABI} 5 \mu \mathrm{M} \mathrm{p}=0.018$; DMSO vs ABI $10 \mu \mathrm{M} \mathrm{p}=0.020$ ) as shown in Fig. 2B.

\section{Effect of ABI on osteoclast/osteoblast markers}

Compared to baseline values, ABI significantly down-modulated osteoclast markers such as TRAP $(p$ $<0.001)$, cathepsin-K $(P<0.001)$, MMP-9 $(\mathrm{P}=0.015)$ and up-regulated the expression of osteoblast' ALP ( $\mathrm{p}=$ $0.015)$ and osteocalcin $(p=0.034)$ genes both in presence and absence of steroids (Fig. 3A and 3B). The reduction of cathepsin-K levels and the increase of osteocalcin expression were confirmed by Western Blot analyses (Fig. $3 \mathrm{~A}$ and $3 \mathrm{~B})$.

\section{Effect of ABI on bone turnover markers in prostate cancer patients}

Forty-nine consecutive patients were recruited. Eighteen of them have the last follow up visit 10 months after the end of treatment. Patients' characteristics are reported in Table 1. Median age was 67 years. Sixteen of them had Gleason Score (GS)=7, six GS $<7$, twentythree GS>7. 16 patients had bone metastases, 18 patients bone and lymph nodes metastases, 9 patients lymph nodes metastases, 3 patients bone and visceral metastases, 1 patient visceral metastases, 1 patient bone metastases and local recurrence, 1 patient bone, lymph nodes and visceral metastases. Twenty patients started zoledronic acid at least three months before beginning ABI treatment. The median number of zoledronic acid doses before ABI therapy was 12.

A significant decrease in CTX values was observed: at baseline the median value was $0.86 \mathrm{ng} / \mathrm{mL}(95 \%$ confidence interval [CI]: 0.84-1.25), and at three, six and nine months it was $0.78 \mathrm{ng} / \mathrm{mL}$ (95\%CI: $0.67-1.01)(\mathrm{p}=$ $0.077), 0.61 \mathrm{ng} / \mathrm{mL}(95 \% \mathrm{CI}: 0.73-1.19)(\mathrm{p}=0.027)$ and $0.66 \mathrm{ng} / \mathrm{mL}(95 \% \mathrm{CI}: 0.38-0.71)(\mathrm{p}=0.006)$, respectively (Table 2, Fig. 4). Compared to median value at baseline 
A
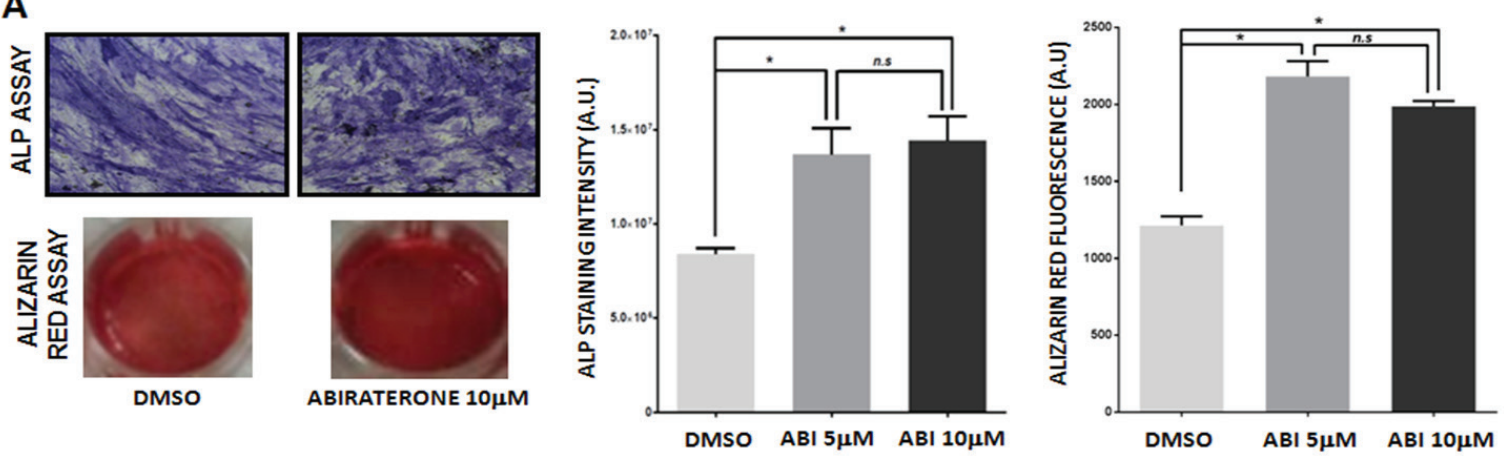

B
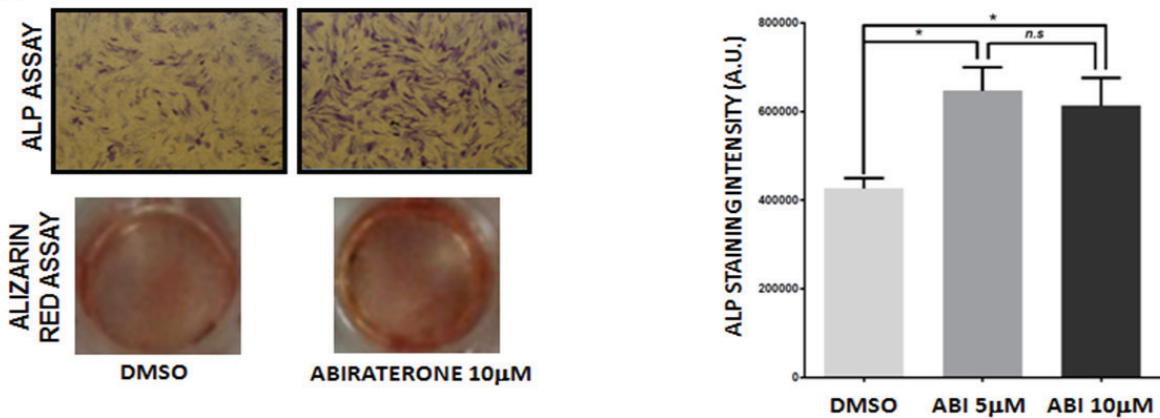

Figure 2: Effect of abiraterone treatment on primary osteoblast. ALP and Alizarin Red assay in treated and untreated osteoclasts (DMSO) in presence $(\mathbf{A})$ and absence $(\mathbf{B})$ of steroids. * $(P<0.05)$.

A
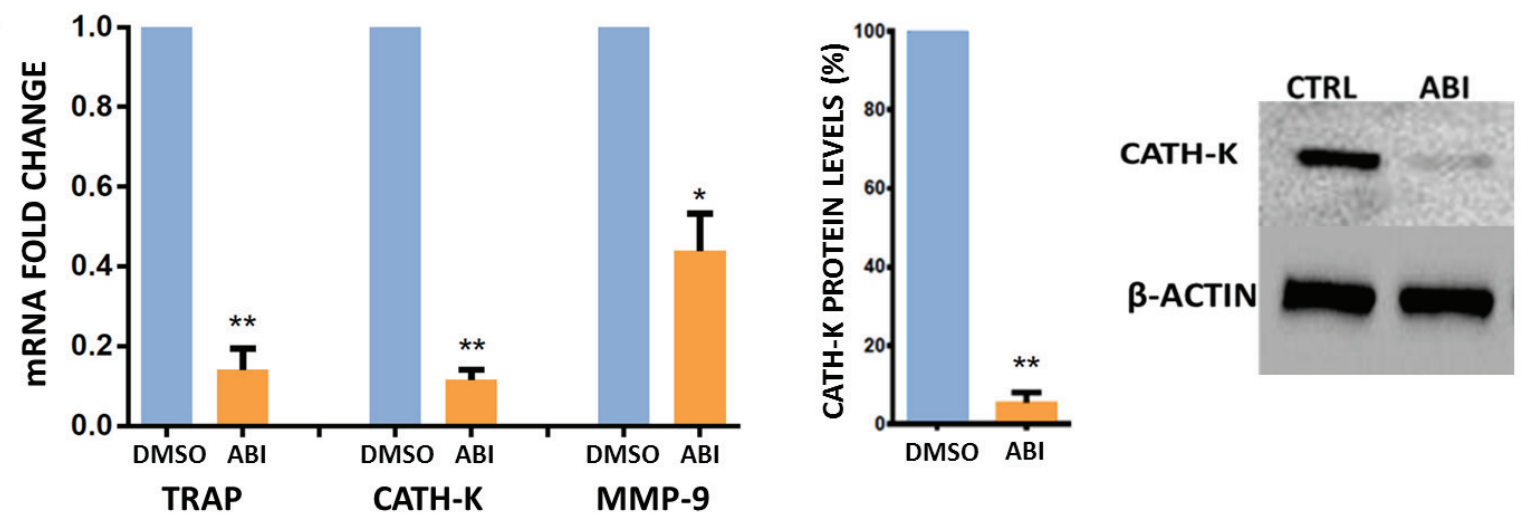

B
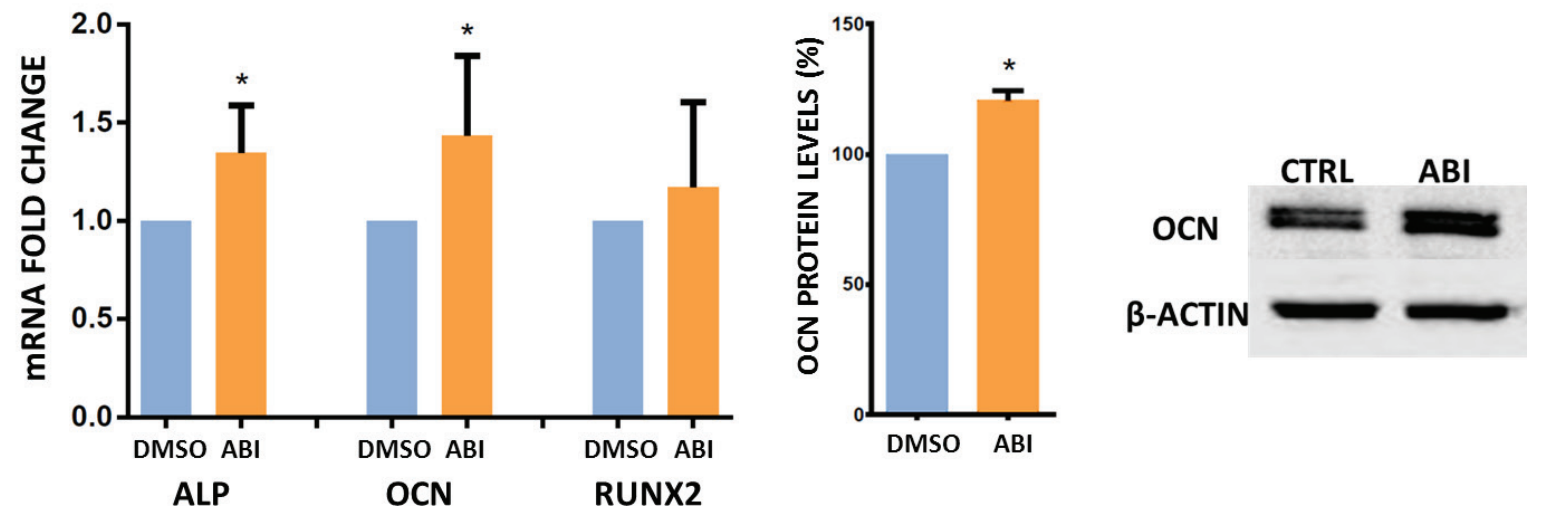

Figure 3: Gene and protein expression analyses. (A). TRAP, CATH-K and MMP-9 mRNA levels (Real Time PCR) and CATH-K protein levels (Western Blot) in treated and untreated osteoclasts (DMSO) cultured with steroids. (B). ALP, OCN, and RUNX2 mRNA levels (Real Time PCR) and OCN protein levels (Western Blot) in treated and untreated osteoclasts (DMSO) cultured with steroids. * $(P$ $<0.05) * *(P<0.001)$. 
Table 2: Difference in median level of bone resorption and formation markers.

\begin{tabular}{|c|c|c|c|c|}
\hline CTX & Baseline ng/mL & Three months ng/mL & $\begin{array}{c}\text { Six months } \\
\mathbf{n g} / \mathbf{m L}\end{array}$ & $\begin{array}{c}\text { Nine months } \\
\mathbf{n g} / \mathbf{m L}\end{array}$ \\
\hline Median, 95\% IC & $0.86,(0.84-1.25)$ & $0.78,(0.67-1.01)$ & $0.61,(0.73-1.19)$ & $0.66,(0.38-0.71)$ \\
\hline $\begin{array}{c}\text { (compare to } \\
\text { baseline) }\end{array}$ & & $\mathrm{p}=0.077$ & $\mathrm{p}=0.027$ & $\mathrm{p}=0.006$ \\
\hline ALP & Baseline U/L & Three months U/L & $\begin{array}{c}\text { Six months } \\
\text { U/L }\end{array}$ & $\begin{array}{c}\text { Nine months } \\
\text { U/L }\end{array}$ \\
\hline Median, 95\% IC & $123,(126-261)$ & $143,(255-382)$ & $126,(200-327)$ & $190,(172-344)$ \\
\hline$p \begin{array}{c}\text { (compare to } \\
\text { baseline) }\end{array}$ & & $\mathrm{p}=0.01$ & $\mathrm{p}=0.62$ & $\mathrm{p}=0.28$ \\
\hline
\end{tabular}

CTX variations analyzed by box and whiskers plot method

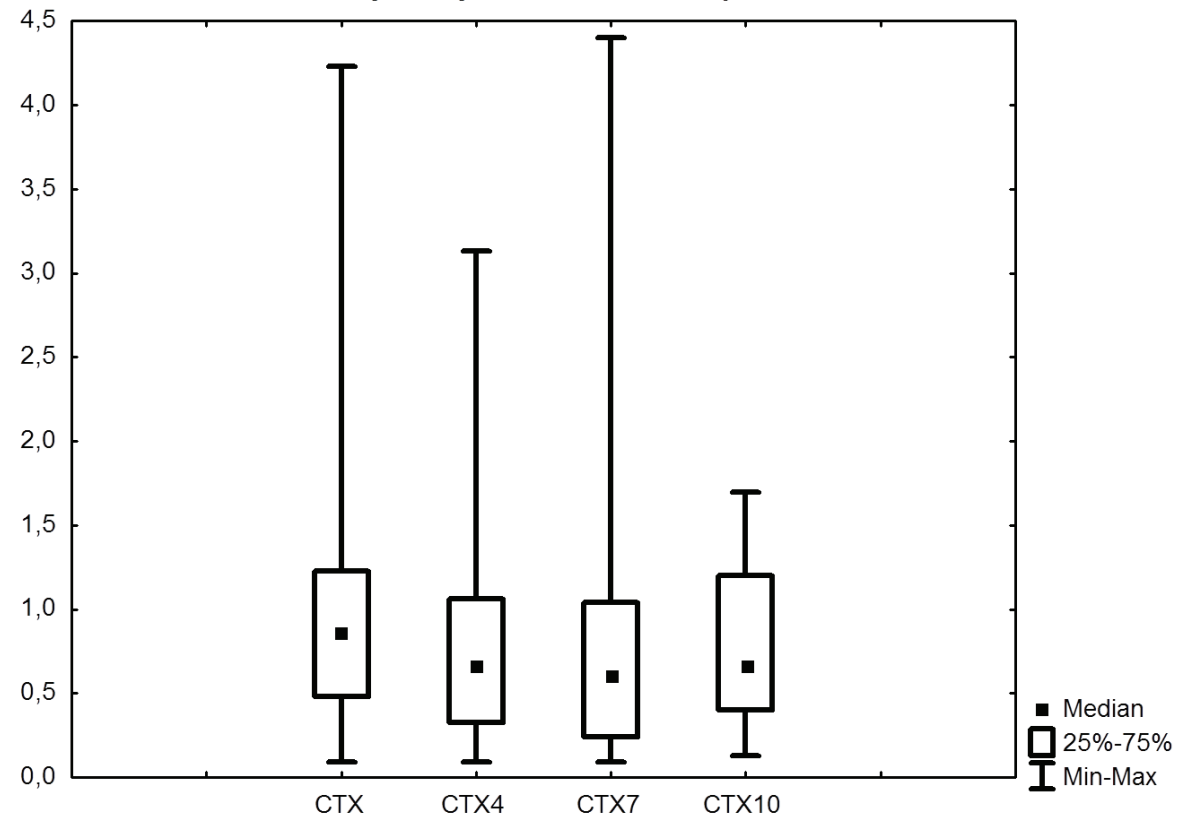

Figure 4: Comparison between CTX at baseline and after three, six and nine months.

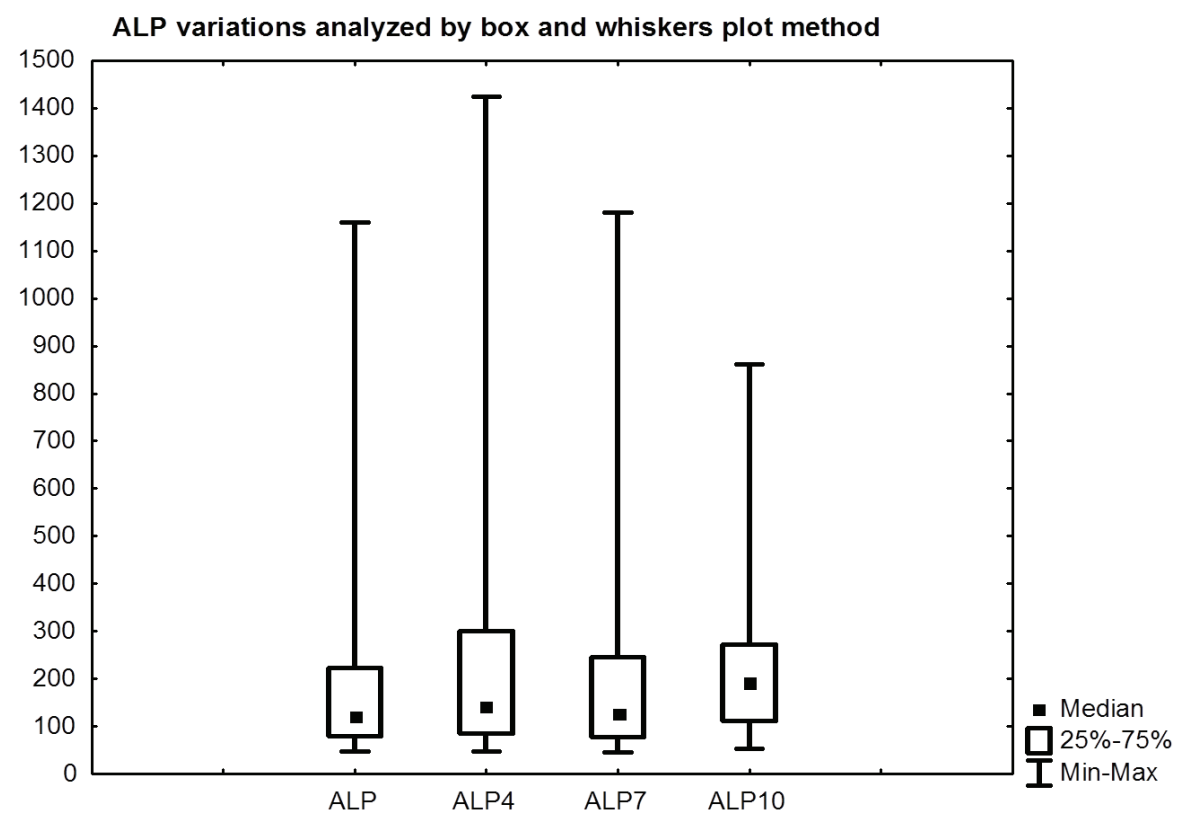

Figure 5: Comparison between ALP at baseline and after three, six and nine months. 
a CTX decrease by $9.3 \%, 29 \%$ and $23 \%$ was observed at three, six and nine months, respectively.

ALP did not show a significant increase, median 123 U/L (95\%CI: 126-261) and 190 U/L (95\%CI 172$344)$ at baseline and nine months $(p=0.28)$, respectively. However, the comparison between ALP at baseline and after 3 months showed a significant increase $(p=0.010)$ (Table 2, Fig. 5). Compared to median value at baseline an ALP increase by $16.3 \%, 2.4 \%$ and $54.5 \%$ was observed at three, six and nine months, respectively.

\section{DISCUSSION}

The results of the present study demonstrate for the first time a direct bone anabolic and an anti-resorptive effect of $\mathrm{ABI}$ both in vitro and in castration resistant prostate cancer patients. Indeed, ABI is able to specifically modulate osteoclast/osteoblast differentiation without generating any cytotoxic and/or proliferative effect at the administrated doses. Moreover, our findings show that ABI regulates gene expression in bone cells modulating mRNA levels of key osteoclastic/osteoblastic genes. Intriguingly, we observed that anabolic and anti-resorptive effects are produced both in presence and absence of steroids suggesting a non-canonical mechanism of action that seems to be, at least in part, androgen-independent.

Recently Bruno et al. reported about an alternative mechanism analyzing the effect of $\mathrm{ABI}$ and other specifc CyP17 inhibitors in an androgen-independent prostate cancer cell line (PC-3) [16]. The treatment induced a rapid release of calcium from the endoplasmic reticulum (ER) resulting in disruption of calcium homeostasis. This, in turns, led to the ER stress response (ERSR), also known as "unfolded protein response" (UPR) through the phosphorylation of the translation elongation factor eIF $2 \alpha$ and the up-regulation of stress response genes, triggering cell cycle arrest. Moreover, recent evidences showed that eIF $2 \alpha$ phosphorylation promotes the activation of ATF4, a key osteoblastic transcriptional factor, leading to osteocalcin up-regulation and down-modulation of a key pro-osteoclastic factor, NFATc1, resulting in bone matrix production [17]. Taken together these data suggest a novel potential molecular mechanism of ABI that, acting through eIF $2 \alpha$ phosphorylation, may promote osteoblastogenesis and inhibit osteoclast-dependent bone resorption. These promising in vitro results provided a strong rationale to design a translational study to investigate the potential modulation of serum bone turnover markers by ABI treatment in a cohort of 49 metastatic castration resistant prostate cancer patients (mCRPC). Our findings showed that in these patients ABI significantly inhibited bone resorption as documented by a decrease of serum CTX values and enhanced new bone formation as shown by an increase of ALP in agreement with in vitro data.

Overall, our pre-clinical and clinical data provide a biological rationale for the high efficacy of ABI treatment in improving multiple skeletal disease specific clinical endpoints as recently documented in the context of phase III clinical trials. Molecules that simultaneous target prostate cancer cells and bone microenvironment could significantly influence future therapeutic approaches in order to achieve a better disease control and management of prostate cancer bone metastases. If further prospective confirmation will be obtained these pivotal results justify a potential synergistic effect of ABI with bone-targeted therapies (bisphosphonates and denosumab).

In conclusion, these findings represent the first evidence of a novel mechanism of ABI directed on bone microenvironment together with the known antitumoral effect on CRPC cells and pave the way to new treatment scenarios for bone metastatic prostate cancer.

\section{MATERIALS AND METHODS}

\section{Primary cell culture}

Human peripheral blood mononuclear cells (PBMCs) were isolated from buffy-coat of 10 male healthy donors by Lympholyte $\mathbb{R}-\mathrm{H}$ density gradient (Cedarlane Laboratories) and monocytes were sorted using beads conjugated anti-human CD14 (Miltenyi Biotech) and cultured for 12 days in RPMI culture medium (Euroclone) supplemented with 10\% fetal bovine serum (Hyclone, Thermo Scientific) or $10 \%$ charcoal stripped serum (Sigma-Aldrich), 100 units $/ \mathrm{ml}$ penicillin, $100 \mathrm{mg} / \mathrm{ml}$ streptomycin (Euroclone), $2 \mathrm{mM}$ L-glutamine (Euroclone), $25 \mathrm{ng} / \mathrm{mL}$ macrophage-colony stimulating factor (M-CSF) and $50 \mathrm{ng} / \mathrm{mL}$ receptor activator of nuclear factor kappa-B ligand (RANKL) (R\&D Systems) to differentiate them into osteoclast. During the differentiation protocol (from day 1 to 12 ), cells were treated with $5-10 \mu \mathrm{M}$ of $\mathrm{ABI}$ acetate (Selleckem) or vehicle as control.

Primary human osteoblasts were differentiated from human mesenchymal stem cells (hMSCs) gently gifted by Cell Culture Laboratory, Department of Biomedicine and Prevention of the University Tor Vergata, Rome. HMSCs were cultured for 21 days in alpha MEM (Euroclone) supplemented with $15 \%$ fetal bovine serum or $15 \%$ charcoal stripped serum, 100 units $/ \mathrm{ml}$ penicillin, 100 $\mathrm{mg} / \mathrm{ml}$ streptomycin, $2 \mathrm{mM}$ L-glutamine, $10 \mathrm{mM}$ betaglycerophosphate (Sigma-Aldrich), $50 \mu \mathrm{M}$ ascorbic acid (Sigma-Aldrich) and $100 \mathrm{nM}$ dexamethasone (SigmaAldrich). During the differentiation protocol (from day 1 to 21 ), cells were treated with $5-10 \mu \mathrm{M}$ of ABI acetate or vehicle as control.

All culture media, growth factors, cytokine and ABI acetate were replaced every 3-4 days [18-19]. 


\section{Osteoclast functional assays}

At the end of the differentiation protocol (day 12) culture medium was removed and cells were fixed with $4 \%$ formaldehyde for 5 minute and stained with leukocyte acid phosphatase (TRAP) kit (Sigma-Aldrich) according to manufacturer's instructions. Stained positive cells $(>3$ nuclei) were then counted [20].

Osteoclasts activity was assessed culturing cells on plates coated with a synthetic inorganic bone mimetic matrix (Osteoassay, Corning). At day 12 the culture medium was removed and plates were filled with sodium hypochlorite solution to evaluate the ability of mature osteoclasts to reabsorb this substrate; pits produced by osteoclasts re-absorptive activity were quantified by ImageJ software.

\section{Osteoblast functional assays}

On day 21 cells were fixed with $4 \%$ formaldehyde for 5 minute and stained with alkaline phosphatase (ALP) kit (Sigma-Aldrich) according to the manufacturer's protocol. ALP positivity was quantified by ImageJ software.

In order to detect bone matrix deposition as a marker of osteoblastic activity cells were fixed with $4 \%$ formaldehyde for 20 minute and stained with alizarin red for 1 hour at room temperature. Alizarin red fluorescence was detected at $470 \mathrm{~nm}$ and quantified by spectrofluorimeter (Tecan Infinite M200Pro) [19].

\section{MTT assay}

Cell viability was evaluated by cell growth determination kit, MTT-based assay (Sigma-Aldrich), and performed according to manufacturer's instructions; the optical density (OD) of the colored complex formed was read by spectrophotometer with $570 \mathrm{~nm}$ wavelength and background absorbance at $690 \mathrm{~nm}$ wavelength was subtracted.

\section{RNA extraction and gene expression analysis}

Total RNA was extracted from osteoclast and osteoblast cells at the end of the differentiation protocol using the Trizol reagent (Invitrogen) according to the manufacturer's instructions. RNA was treated with DNase buffer and DNase (DNAse Turbo, Applied Biosystems) to avoid genomic DNA contamination. cDNA was produced using the High Capacity cDNA Reverse Transcription kit (Applied Biosystems) according to the manufacturer's instructions. mRNA levels were measured by quantitative real-time polymerase chain reaction (qRT-PCR) using TaqMan Gene Expression Assays in 7900HT Real-
Time PCR System (Applied Biosystems). Tartrate resistant acid phosphatase (TRAP) (Hs00356261_m1), cathepsin-K (Hs00166156_m1), metalloproteinase-9 (Hs00234579_m1), alkaline phosphatase (ALP) (Hs01029144_m1), osteocalcin (Hs00234160 m1) and runt-related transcription factor 2 (RUNX2) (Hs00231692_ml) expression levels were normalized to the endogenous housekeeping gene glucuronidase beta (GUSb) (Hs99999908 m1) in both untreated and treated samples using the $\Delta \mathrm{CT}$ calculation. Subsequently relative expression levels in treated samples were normalized to the mRNA levels detected in control samples using the $\Delta \Delta \mathrm{CT}$ calculation [21].

\section{Protein extraction and western blot analysis}

Cell lysates was obtained using radioimmunoprecipitation assay buffer (RIPA buffer) (Sigma-Aldrich) and quantified using DC protein assay kit (Bio-Rad). Twenty mg of the total protein extract from each sample was loaded on $8 \% / 15 \%$ SDS-PAGE gels, transferred onto nitrocellulose membranes through TransBlot Turbo Transfer System (Bio-Rad) and incubated in a blocking buffer (TBST 1X with 5\% non-fat dry milk) for one hour. Mouse monoclonal anti-human Cat-K (Santa Cruz Biotechnologies), rabbit polyclonal anti-human OCN (Santa Cruz Biotechnologies) and mouse anti-human Actin- $\beta$ (Sigma-Aldrich) were incubated for 2 hours at room temperature. Anti-rabbit/mouse HRT-coniugated antibody (Abcam) was used and the chemiluminescence signal detected using ChemiDoc (Bio-Rad) and Quantity One software (Bio-Rad) to quantify the bands' signal intensity.

\section{Patients}

Patients with metastatic castration resistant prostate cancer (mCRPC) with or without bone metastases in clinical progression following treatment with docetaxel and enrolled in the ABI acetate expanded access program at the Division of Medical Oncology-S. Luigi Hospital, Orbassano were prospectively assessed. ABI acetate was administered at the dose of $1.000 \mathrm{mg}$ daily with prednisone $5 \mathrm{mg}$ twice a day in combination with luteinizing hormone releasing hormone analogue until radiological or serological progression. A subgroup of patients was also treated with zoledronic acid at standard unchanged doses in the last three months before starting ABI. All patients were evaluated for bone formation and resorption.

Serum alkaline phosphatase (ALP) as a marker of osteoblast activity and serum c-telopetide of type-I collagen (CTX) as a marker of bone resorption were assessed every 3 months at a centralized laboratory at San Luigi Hospital Orbassano. Total ALP was evaluated by standard automated analytical procedures (Architect, 
Abbott) and normal levels ranged between 30 and 120 U/L. Serum CTX level was measured using a commercial ELISA kit (IDS-iSYS CTX-I, Immunodiagnostic Systems Ltd). Normal values, minimum detectable concentrations, intra- and inter assay coefficients of variation of CTX were as follows: $0.12-0.75 \mathrm{ng} / \mathrm{mL}, 0.023 \mathrm{ng} / \mathrm{mL}, 3.2$ and $6.3 \%$.

\section{Statistical analysis}

In vitro data were analyzed using the Student $\mathrm{t}$ test and One-Way ANOVA test followed by Tukey's multiple comparison tests. The graphics processing and statistical tests were performed using the program GraphPad Prism (San Diego, CA).

For marker analyses Wilcoxon's matched pairs signrank test was used to compare pair data at baseline and after 3, 6 and 9 months of treatment. All $p$-values reported were two-sided; $p$-values $<0.05$ were chosen for statistical significance. Statistical computation was performed using the SPSS for Windows software package.

\section{ACKNOWLEDGMENTS}

We thank Dr. Francesca Agostini of Cell Culture Laboratory, Department of Biomedicine and Prevention of the University Tor Vergata that kindly provided hMSC used in our experiments.

\section{FUNDING}

This research received no specific third-party funds or grant.

\section{CONFLICTS OF INTEREST}

The authors of this manuscript have no conflicts of interest to disclose.

\section{REFERENCES}

1. Santini D, Galluzzo S, Zoccoli A, Pantano F, Fratto ME, Vincenzi B, Lombardi L, Gucciardino C, Silvestris N, Riva E, Rizzo S, Russo A, Maiello E, Colucci G, Tonini G. New molecular targets in bone metastases. CancerTreat Rev. 2010; 36Suppl 3:S6-S10.

2. O’Donnell A, Judson I, Dowsett M, Raynaud F, Dearnaley D, Mason M, Harland S, Robbins A, Halbert G, Nutley B, Jarman M. Hormonal impact of the 17alpha-hydroxylase/ $\mathrm{C}(17,20)$-lyase inhibitor abiraterone acetate (CB7630) in patients with prostate cancer. Br J Cancer. 2004; 90:23172325.

3. Barrie SE, Potter GA, Goddard PM, Haynes BP, Dowsett M, Jarman M. Pharmacology of novel steroidal inhibitors of cytochrome P450(17) alpha (17 alpha-hydroxylase/C17-20 lyase). J Steroid Biochem Mol Biol. 1994; 50:267-273.

4. De Bono JS, Logothetis CJ, Molina A, Fizazi K, North S, Chu L, Chi KN, Jones RJ, Goodman OB Jr, Saad F, Staffurth JN, Mainwaring P, Harland S, et al. ABI and increased survival in metastatic prostate cancer. N Engl J Med. 2011; 364:1995-2005.

5. Fizazi K, Scher HI, Molina A, Logothetis CJ, Chi KN, Jones RJ, Staffurth JN, North S, Vogelzang NJ, Saad F, Mainwaring P, Harland S, Goodman OB Jr, et.al. Abiraterone acetate for treatment of metastatic castrationresistant prostate cancer: final overall survival analysis of the COU-AA-301 randomised, double-blind, placebocontrolled phase 3 study. Lancet Oncol. 2012;13:983-992.

6. Ryan CJ, Smith MR, de Bono JS, Molina A, Logothetis CJ, de Souza P, Fizazi K, Mainwaring P, Piulats JM, Ng S, Carles J, Mulders PF, Basch E, et al. Abiraterone in metastatic prostate cancer without previous chemotherapy. N Engl J Med. 2013; 10;368:138-148.

7. Kawano H, Sato T, Yamada T, Matsumoto T, Sekine K, Watanabe T, Nakamura T, Fukuda T, Yoshimura K, Yoshizawa T, Aihara K, Yamamoto Y, Nakamichi Y, et al. Suppressive function of androgen receptor in bone resorption. Proc Natl Acad Sci USA. 2003; 100:9416-9421.

8. Wiren KM, Semirale AA, Zhang XW, Woo A, Tommasini SM, Price C, Schaffler MB, Jepsen KJ. Targeting of androgen receptor in bone reveals a lack of androgen anabolic action and inhibition of osteogenesis: a model for compartment-specific androgen action in the skeleton. Bone. 2008;43:440-451.

9. Chiang C, Chiu M, Moore AJ, Anderson PH, GhasemZadeh A, McManus JF, Ma C, Seeman E, Clemens TL, Morris HA, Zajac JD, Davey RA. Mineralization and bone resorption are regulated by the androgen receptor in male mice. J Bone Miner Res. 2009;24:621-631.

10. Falahati-Nini A, Riggs BL, Atkinson EJ, O'Fallon WM, Eastell R, Khosla S. Relative contributions of testosterone and estrogen in regulating bone resorption and formation in normal elderly men. J Clin Invest. 2000;106:1553-1560.

11. Kousteni S, Chen JR, Bellido T, Han L, Ali AA, O'Brien CA, Plotkin L, Fu Q, Mancino AT, Wen Y, Vertino AM, Powers CC, Stewart SA, Ebert R, Parfitt AM, Weinstein RS, Jilka RL, Manolagas SC. Reversal of bone loss in mice by nongenotropic signaling of sex steroids. Science. 2002; 298:843-846.

12. Kousteni S, Bellido T, Plotkin LI, O’Brien CA, Bodenner DL, Han L, Han K, DiGregorio GB, Katzenellenbogen JA, Katzenellenbogen BS, Roberson PK, Weinstein RS, Jilka RL, Manolagas SC. Nongenotropic, sex-nonspecific signaling through the estrogen or androgen receptors: dissociation from transcriptional activity. Cell. 2001; 104:719-730.

13. Duc I, Bonnet $\mathrm{P}$, Duranti V, Cardinali S, Rivière A, De Giovanni A, Shields-Botella J, Barcelo G, Adje N, Carniato $\mathrm{D}$, Lafay J, Pascal JC, Delansorne R. In vitro and in vivo models for the evaluation of potent inhibitors of male rat 
17alpha-hydroxylase/C17,20-lyase. J Steroid BiochemMol Biol. 2003; 84:537-542.

14. Richards J, Lim AC, Hay CW, Taylor AE, Wingate A, Nowakowska K, Pezaro C, Carreira S, Goodall J, Arlt W, McEwan IJ, de Bono JS, Attard G. Interactions of abiraterone, eplerenone, and prednisolone with wild-type and mutant androgen receptor: a rationale for increasing abiraterone exposure or combining with MDV3100. Cancer Res. 2012; 72:2176-2182.

15. vanSoest RJ, van Royen ME, de Morrée ES, Moll JM, Teubel W, Wiemer EA, Mathijssen RH, de Wit R, van Weerden WM. Cross-resistance between taxanes and new hormonal agents abiraterone and enzalutamide may affect drug sequence choices in metastatic castration-resistant prostate cancer. Eur J Cancer. 2013; 49:3821-3830.

16. Bruno RD, Gover TD, Burger AM, Brodie AM, Njar VC. 17alpha Hydroxylase/17,20 lyase inhibitor VN/124-1 inhibits growth of androgen-independent prostate cancer cells via induction of the endoplasmic reticulum stress response. Mol Cancer Ther. 2008; 7:2828-2836.

17. Hamamura K, Tanjung N, Yokota H. Suppression of osteoclastogenesis through phosphorylation of eukaryotic translation initiation factor 2 alpha. J Bone Miner Metab. 2013; 31:618-628.

18. Susa M, Luong-Nguyen NH, Cappellen D, Zamurovic N, Gamse R. Human primary osteoclasts: in vitro generation and applications as pharmacological and clinical assay. $\mathrm{J}$ Transl Med. 2004; 2:6.

19. He W, Mazumder A, Wilder T, Cronstein BN. Adenosine regulates bone metabolism via $\mathrm{A} 1, \mathrm{~A} 2 \mathrm{~A}$, and $\mathrm{A} 2 \mathrm{~B}$ receptors in bone marrow cells from normal humans and patients with multiple myeloma. FASEB J. 2013; 27:3446-3454.

20. Yen ML, Hsu PN, Liao HJ, Lee BH, Tsai HF. TRAF-6 dependent signaling pathway is essential for TNF-related apoptosis-inducing ligand (TRAIL) induces osteoclast differentiation. PLoS One. 2012; 7:e38048.

21. Livak KJ, Schmittgen TD. Analysis of relative gene expression data using real-time quantitative PCR and the 2(-Delta Delta C(T)). Method Methods. 2001; 25:402-408. 